\title{
The role of emotion in ethics and bioethics: dealing with repugnance and disgust
}

Joshua May's paper in this issue is an empirical study of the kinds of emotional responses that people have to human reproductive cloning (see page 26). This study gets its start from the strong claims made against reproductive cloning by Leon Kass ${ }^{1}$ and John Kekes. ${ }^{2}$

May's paper is a good example of clearly targeted empirical research that clearly pinpoints empirical claims made in ethics or bioethics. Leon Kass claims that it is disgust or repugnance that most people feel-'the widespread repugnances of humankind'-while John Kekes claims that these are behaviours that just about everybody in contemporary Western societies would find disgusting'. So showing that this repugnance is not widespread or that just about everybody does not find reproductive cloning disgusting undermines these claims. May's study gives us some decent and initial reason for thinking that these empirical claims are at best difficult to substantiate and at worst, false.

But what generally are we to say about the role of emotions in ethics and in ethical judgement? We tend to sharply distinguish 'mere' emotions or emotional responses from reasoned or rational argument. Clearly, it would seem, if we are to make claims about rightness or wrongness they should be on the basis of reasons and rational argument. Emotions look to be outside of this paradigm concerned as they are with our responses to the world rather than the world itself and the clear articulation of inferential relationships within it. Most importantly emotions are felt subjectively and so cannot lay any generalised claim on others (particularly others who do not feel as the arguer does). The subjectivity of emotions means that they cannot function in arguments because, unless they are universal, they cannot form the basis of a claim on another person. The reason they cannot form this basis is because that other person may not have that emotion: relying on it means the argument can only apply to those who do. An argument that relies on feeling particular emotions, particularly emotions that we don't all feel in the same way, is weak to that extent and certainly weaker than one that does not.

In the case at hand, repugnance or disgust only have persuasive power to those who feel these emotions in response to human reproductive cloning. If all people felt one or the other, then claims based on an appeal to repugnance or disgust would have persuasive power over all of us. But even if these were generally or commonly felt emotions here, such persuasive power would be distinct from an argument's having persuasive power over us because of the reasons it provides for us independently of contingently felt emotions. An argument then that is based on an appeal to emotion apparently as Kass' and Kekes' apparently are, can, at best, be only as strong as the generalisability of the empirical claim about the relevant emotion.

But it is far from obvious that we should take this general attitude to emotional responses in ethics and to arguments in ethics. One kind of objection to this dichotomy between emotion and reason lays claims to the ethical importance of respect: we should respect people and their emotions. As such belittling and dismissing emotional responses is a political move involving misuse of power, perhaps the tyranny of reason, and correspondingly, disrespect for those who have those emotions. The background to this objection makes reference to, as it were, the politics of argument. Restricting or limiting the contribution that particular individuals can make to conversation, undermines and devalues their voice. What matters here is that everyone has the opportunity to have their voice heard. Excluding people them on the basis of the form of their contribution, excluding someone because their contribution is emotional rather than reasoned is to unfairly privilege one form contribution and marginalise others.

Though common in various quarters, this is not the right move to make here. The distinction between reason and emotion described above relies on a view of argument that aims to extend beyond the messy, real world politics of the empirical world. One way of making progress on this view of argument is to abstract away from the real-world differences between individuals and to reflect on considerations that are either features of people independent of their context or are of a sort that people who are open to these claims might take as relevant, independent of their context. This abstraction helps in the move to considering reasons as relevant. On this view, arguments aspire to appeal to reasons that apply to all people independently of context and as possessors of the ability to reason. That is, arguments function by making an appeal to general features of people. "So the reasons anyone should accept that $\mathrm{q}$ follows from 'If $\mathrm{p}$ then $\mathrm{q}$ ' and $\mathrm{p}$ are reasons that apply to him or her in virtue of his or her logical or reasoning capacities generally-those features that he or she holds in common with all beings capable of logic and reason". (Dunn et al., 2012, Sheehan and Dunn, 2013) This is not say that arguments always or mostly succeed but the extent to which they do not is the extent to which they fail in this abstraction and in this appeal to reasons. As was suggested above, an appeal to contingently felt emotions like repugnance or disgust seems unlikely from the outset to come close to meeting this aspiration.

Having said this, emotions are clearly the stuff of ethics in an important respect. Glossing over some important distinctions in moral philosophy, the 'passions' (our emotions, attitudes and desires) make ethical issues and choices things that we care about. When an ethical decision is at its most difficult, on the face of it this is because it really matters what we do and because we fell passionate about it. If cool rational deliberation was clearly always appropriate or we had internalised a straightforward algorithm of rational argument, it seems we would have lost a key feature of our ability to be ethical and to engage ethically with the world.

None of this is to say that our passions are necessarily reliable or should be taken as guides to what is right or wrong. Nor does it mean that our emotions should be respected-even if those who have them should be. What it does mean is that we should pay careful attention to our 
emotional responses and that we should carefully unpack their basis in the light of the kinds of considerations and reasons that might apply more generally and independently of context.

\section{DISGUST AND REPUGNANCE}

'Disgust advocates', as Kelly ${ }^{3}$ calls them, (in)famously make two claims: one empirical and one normative. The empirical claim, that most/some/normal people are disgusted by human cloning, is Joshua May's target in his study 'Emotional reactions to human reproductive cloning' (see page 26). The normative claim is that in various ways, this response shows us something important about the ethics of this practice. I take it that the second is captured by (i) Kass' claim about the wisdom of this repugnance-that is, the wisdom of our feeling this particular emotion-and (ii) the claims about intuition and the relationship between intuition and argument.

The normative claim is distinct however and although it relies on an empirical claim, it is not clear how far it need rely on being tied to the specific emotions of disgust or repugnance. One response by Kass and colleagues might be to withdraw from being quite so specific about the precise emotion involved. People will vary in how exercised they become about reproductive cloning and this might express itself in how they express or characterise how they feel.

There is something to this line of response. If I think of something that I take, on the face of it, to be extremely morally reprehensible as indicated by my basic emotional response, it is unclear quite how to characterise this emotion. Perhaps I am someone who doesn't readily feel disgust or repugnance or perhaps these are not the kinds of examples that move me in precisely the 'disgust' way. Neither of these possibilities rules out my having strong emotions that are indicative or reflective of my general moral condemnation of the act in question.

There are some important parallel considerations and lessons that we might learn or explore in future research. May notices that in his study "greater acceptability of the practice in my sample may well be due to the clear explanation of cloning provided, which does some work to dispel common myths about clones being, say, mindless drones used to harvest organs" (see page 28). Of course the presentation of the details of the case clearly can make a difference to response, providing a medically situated context with balanced rationales for wanting to use reproductive cloning might mean that people are less likely to be moved as far as repugnance or disgust.

I take it that this shows us something again about the distinction between reason and emotion. The move to balanced rationales and clear explanations might move us away from heightened, very specific emotions like repugnance and disgust perhaps to a general and vague feeling of unease. But saying why we feel might feel uneasy or giving reasons for the uneasiness when and if we feel it, looks to be an endeavour that does not necessarily rely on the kind of empirical claims that the 'disgust advocates' seem to presuppose and which May does a good job of undermining.

\section{REFERENCES}

1 Kass LR. The wisdom of repugnance: why we should ban the cloning of humans. New Repub 1997;216:17-26.

2 Kekes J. A case for conservatism. Ithaca, NY: Cornell University Press, 1998.

3 Kelly D. Yuck: the nature and moral significance of disgust. Cambridge, MA: MIT Press, 2001.

4 Sheehan M, Dunn M. On the Nature and Sociology of Bioethics. Health Care Analysis 2013;21:54-69.

5 Dunn M, Sheehan M, Hope T, et al. Towards methodological innovation in empirical ethics research. Cambridge Quarterly of Healthcare Ethics 2012;21: 466-80. 